\title{
Lipomatous hypertrophy of the interatrial septum: an unusual intraoperative finding
}

\author{
M Bhattacharjee, M C Neligan, P Dervan
}

\begin{abstract}
Lipomatous hypertrophy of the interatrial septum was an incidental finding in a man of 45 undergoing coronary artery bypass grafting for unstable angina. He was not overweight and did not have any rhythm disturbances. The diagnosis was made on frozen section.
\end{abstract}

\section{Case report}

A 45 year old man presented in August 1989 to the National Cardiac Surgical Unit, Dublin with unstable angina that required emergency grafting.

In August 1988 he had had an inferior myocardial infarction from which he made an uneventful recovery but was left with angina of effort. This remained stable on medical treatment. Two months before operation the angina became unstable and angiography confirmed triple vessel disease. $\mathrm{He}$ was a moderately heavy smoker with a family history of ischaemic heart disease: his father died at the age of 51 from a myocardial infarction. Forty eight hours before operation he was admitted to a coronary care unit. He needed intravenous nitrates to control his angina.

He looked fit and was normotensive and in sinus rhythm. There was no evidence of congestive heart failure. He had varicose veins in both legs.

Laboratory investigations were normal except for total proteins $(85 \mathrm{~g} / 1$ (normal range 58-80)); albumin (54 g/1 (35-53)); and alanine aminotransferase (45 IU/1 (5-35)). The electrocardiogram showed sinus rhythm.

Within hours of his transfer to our unit a coronary artery bypass graft operation was started. Total cardiopulmonary bypass was established through a single aortic cannula and a composite venous cannula after a median sternotomy. Then a lesion of the interatrial septum in front of the right superior pulmonary vein was noticed. At this point bicaval cannulation was carried out and the right atrium was opened to show a firm brownish mass in the interatrial septum.

The mass was regarded as a possible tumour and multiple biopsy specimens were taken for rapid diagnosis from frozen sections to exclude malignancy. Because the appearance of the specimens suggested lipomatous hypertrophy of the interatrial septum we proceeded to do the coronary artery bypass grafting. Before we closed the right atrium we took further biopsy specimens for paraffin sectioning. We used reversed long saphenous vein segments for bypass grafting to the left anterior descending, right coronary, and obtuse marginal arteries.

He came off bypass with no problems other than a transient nodal rhythm which did not affect his haemodynamic state. After operation he remained in sinus rhythm and his remaining hospital stay was uncomplicated.

A paraffin section of the biopsy specimen (figure) showed fragments of normal myocardium infiltrated by mature adipose tissue which surrounded large and small groups of myocytes. The adipose cells were normal and there was no evidence of malignancy. The epicardium contained occasional clusters of lymphocytes. These features are characteristic of lipomatous hypertrophy of the interatrial septum

\section{Discussion}

This is the second case of lipomatous hypertrophy of the interatrial septum detected as an incidental finding at operation. The first was reported by McAllister and Fenoglio in $1978 .^{1}$ We believe that this is the first time this tumour-like lesion has been diagnosed by frozen section examination. Accurate histological diagnosis is not difficult if the possibility of lipomatous hypertrophy is borne in mind. Otherwise a low grade liposarcoma is likely to be diagnosed. A firm brown tumour arising in the interatrial septum in a previously fit young man with earlier evidence of arrhythmia certainly did not suggest lipomatous hypertrophy of the interatrial septum. So it was only after it was unequivocally shown that there was no evidence of malignancy in the frozen sections that we continued with bypass grafting.

Lipomatous hypertrophy of the interatrial septum was first reported by Prior in 1964 as an unusual necropsy finding in five patients (mean age 73 ). ${ }^{2}$ Cases have been reported in patients aged 22 to 88 years. ${ }^{3}$ In 1971 Hutter and Page reported on the clinicopathological findings in 10 patients and recognised the high incidence of atrial arrhythmias and a deformed $P$ wave on the electrocardiogram (previously described as a "dome and dip" configuration). ${ }^{4}$ When we reviewed our patient's past electrocardiograms we found similar P wave characteristics in leads II, III, and $\mathrm{aVF}$ in electrocardiograms recorded on 


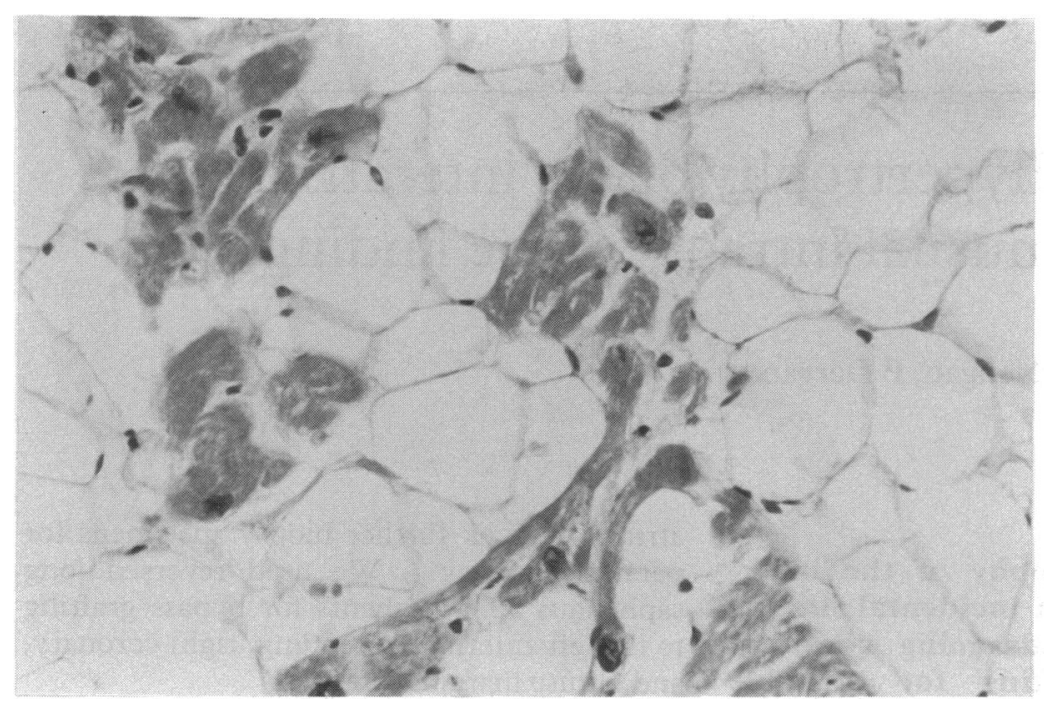

Figure Myocardial fibres surrounded by mature adipose tissue. Haematoxylin and eosin stain; original magnification, $\times 200$. valve of the fossa ovalis; $(c)$ the absence of any other, more likely explanation for septal thickening. ${ }^{6}$ They also add that the presence of $\mathrm{P}$ wave abnormalities such as increased voltage and duration or notching supports the diagnosis. Accumulation of septal fat where there is internodal atrial myocardium probably accounts for the reported arrhythmias and $P$ wave configuration. ${ }^{78}$ Applegate et al also reported two patients with lipomatous hypertrophy of the interatrial septum in whom magnetic resonance imaging was done. ${ }^{9} \mathrm{We}$ know of only one patient in whom lipomatou hypertrophy of the interatrial septum was associated with multiple subcutaneous lipomas. ${ }^{10}$ On the other hand, cardiac lipomas, encapsulated masses of mature fat surrounded by myocardium, are known to be associated with berry aneurysms and tuberous sclerosis.

Prior believes that the pathogenesis of lipomatous hypertrophy of the interatrial septum is related to the hypertrophy of normal fatty tissue present in the interatrial septum. ${ }^{2}$ McAllister and Fenoglio suggest that it is a hyperplasia of primordial fat. ${ }^{1}$ Neither propose a neoplastic process as the essential abnormality.

Our patient will have to be closely followed up because the infiltrative process in lipomatous hypertrophy of the interatrial septum seems to be progressive and symptoms of obstructions may require excision of the lesion. $^{3}$ in 1982 the first patient appeared. ${ }^{5}$ This was diagnosed by computed axial tomographic scanning and the pattern of fat deposition was shown. The fat was distributed in a bilobed manner about the fossa ovalis, which itself was spared. The fatty nature of the lesion was apparent from the characteristic Hounsfield number. The cephalad mass of fat was continuous with the subepicardial adipose tissue. Isner et al went so far as to suggest that in an obese, elderly patient with supraventricular arrhythmias in whom the cause cannot be identified lipomatous hypertrophy of the interatrial septum should be suspected. Had we suspected lipomatous hypertrophy of the interatrial septum in our patient cross sectional echocardiography would have given us a preoperative diagnosis. Fyke et al suggested the following guidelines for making the diagnosis on echocardiography: (a) the characteristic bilobed appearance of the atrial septum when the beam is directed through the region of the fossa ovalis; (b) a thickness of $\geqslant 15 \mathrm{~mm}$ postero-superior or antero-inferior to the
1 McAllister HA Jr, Fenoglio JJ Jr. Tumours of the cardiovascular system. In: Atlas of tumor pathology. Second series. Fascicle 15. Washington DC: Armed Forces Institute of Pathology, 1978:5-46.

2 Prior JT. Lipomatous hypertrophy of cardiac interatrial septum. Arch Pathol 1964;78:11-5.

3 Case Records of the Massachusetts General Hospital. Case 10-1989. N Engl J Med 1989;320:652-60.

4 Hutter AM Jr, Page DL. Atrial arrhythmias and lipomatous hypertrophy of the cardiac interatrial septum. Am Heart 1971;82:16-21.

5 Isner JM, Swan CS II, Mikus JP, Carter BL. Lipomatous hypertrophy of the interatrial septum. In vivo diagnosis. Circulation 1982;66:470-3. of lipomatous hypertrophy of the atrial septum by two dimensional echocardiography. $J$ Am Coll Cardiol 1983; 1:1352-7.

7 Meredith J, Titus JL. Anatomical atrial connections betatrial septum in the human heart. Am Heart J 1979; 98:194-9.

9 Applegate PM, Tajik AJ, Ehman RL, Julsrud PR, Miller FA Jr. Two dimensional echocardiographic and magnetic resonance imaging observations in massive lipomatous hypertrophy of the atrial septum. Am J Cardiol 1987; 59:489-91.

10 Levine RA, Weyman AE, Dinsmore RE, et al. Non-invasive tissue characterization: diagnosis of lipomatous hypertrophy of atrial septum by nuclear magnetic resonance imaging. J Am Coll Cardiol 1986;7:688-92.
6 Fyke FE III, Tajik AJ, Edwards WD, Seward JB. Diagnosis ween sinus and A-V node. Circulation 1968;37:566-79.

8 Sweeney LJ, Rosenquist GC. The normal anatomy of the 